\title{
Optimizing the Reduction of Total Suspended Solids in Pump Water from Fish Factories Through Electrocoagulation using Response Surface Methodology
}

\author{
Edwar Aguilar-Ascón', Walter Neyra-Ascón', Miguel Albrecht-Ruiz², \\ Alonso Ibarra-Basurto ${ }^{3}$ \\ 1 Universidad de Lima, Instituto de Investigación Científica (IDIC), Av. Javier Prado Este 4600, Surco, Lima, Perú \\ 2 Instituto Tecnológico de la Producción (DIDITT), Carretera a Ventanilla Km. 5, 6. Callao, Perú \\ ${ }^{3}$ Pesquera Diamante S.A., Amador Merino Reyna 307, Edificio Nacional, piso 12 y 13, San Isidro, Lima, Perú \\ * Corresponding author's e-mail: eaguilaa@ulima.edu.pe
}

\begin{abstract}
This study aims to optimize the removal of total suspended solids (TSS) in pump water from fish flour factories through electrocoagulation technology and to determine the effects of the main operation parameters. Pump water has high conductivity $(40.1 \mathrm{mS})$, due to the presence of dissolved salts and contains high concentration of organic substances $(12,360 \mathrm{mg} / \mathrm{L}$ of TSS and $520 \mathrm{mg} / \mathrm{L}$ of fats). In this study, pump water was treated in an electrocoagulation reactor with aluminum electrodes using Response Surface Methodology with a $3^{\mathrm{k}}$ factorial design based on two factors, current intensity (I) of 8-13 A and treatment time (t) of 20-40 minutes. The percentage of TSS removed from the water was used as the response variable. The results revealed that I and t significantly $(p<0.05)$ influenced the process. In accordance, the optimal operational parameters for TSS removal were $\mathrm{I}=13 \mathrm{~A}$ and $\mathrm{t}=$ 30 minutes. Using these conditions, TSS removal efficiency of $99.9 \%$ was achieved. The sewage sludge generated with these optimal process conditions indicated $19.3 \%$ of ash content, $6.2 \%$ of salt, $1.7 \%$ of aluminum, $0.3 \%$ of iron, $0.4 \%$ of potassium, $256 \mathrm{ppm}$ of zinc, and $2.1 \%$ of phosphorus. Hence, the results of this study affirm that electrocoagulation can be considered as a solution for marine pollution caused by fishing industries.
\end{abstract}

Keywords: Total suspended solids (TSS), electrocoagulation, fishmeal, fish pumping water, response surface methodology, optimization.

\section{INTRODUCTION}

The Peruvian anchovy (Engraulis ringens) is mainly used as a raw material in the production of fish flour. This industry utilizes significant volumes of water and generates abundant quantity of wastewater [Putra et al., 2020; Omil et al., 1996]. Dispatching fish from ships to flour factories involves using sea water as the transportation fluid. This water is known as "pump water," and it is an effluent containing around $3.5 \%$ of organic matter, either as dissolved solids, suspended solids, or oils and fats [Espinoza, 2016]. Before being discharged into the sea, pump water is usually treated to decrease its organic matter content and consequently, prevent environmental pollution. In this regard, the Peruvian Ministry of Environment has issued guidelines for the management of these sewage waters, fixing the maximum allowed content for suspended solids at $700 \mathrm{ppm}$ and for oils and fats at $350 \mathrm{ppm}$ [Ministry of Environment, 2018].

Presently, pump water is treated with coagulants and flocculants to reduce the concentration of organic matter to comply with the environmental regulations [Loza Pacheco, 2014]. This treatment reports a removal efficiency of $85.8 \%$ and $99.2 \%$ for TSS and fats, respectively [Cristóvão et al., 2014]; however, this treatment process increases the concentration of inorganic salts in 
the treated water and favors the buildup of salts in solids [Espinoza Villegas, 2016], thereby restricting the possibility of using it as animal feed or fertilizer.

As part of the search for more affordable technologies for treating the effluents of fishing industries, there have been reports on treatment processes in continuous flow aerobic bioreactors that attain chemical oxygen demand (COD) of $86 \%$ and TSS removal efficiency of 37\% [Ching and Redzwan, 2017] as well as in anaerobic reactors with COD removal efficiencies of up to $94 \%$ [Putra et al., 2020]. The technologies using aerobic or anaerobic bioreactors are both affordable and ecofriendly, but they require long treatment times to reach maximum pollutant removal efficiency; hence, they are hardly scalable for pump water flows of approximately $200 \mathrm{~m}^{3} /$ hour from fish flour factories [Espinoza Villegas, 2016].

Electrocoagulation is one of the alternative technologies applied to different types of wastewater and offers advantages, such as low-cost installation and operation, a lower production of sludge volumes, [Elkacmi et al., 2020], high removal efficiency, no requirement of additional chemicals, and shorter treatment times. [Castañeda et al., 2020]. This technology is an electrochemical process, whereby two electrodes, called anode and cathode, receive electrical current supply [AlJaberi, 2019]. It is from the anode or sacrificial electrode (usually made of aluminum or iron), where metallic cations are generated and hydrolyzed in situ to form coagulants [Rodríguez et al., 2010], which agglomerate colloidal particles. This process separates pollutants through flotation and precipitation due to the small hydrogen bubbles generated by the cathode [Akansha et al., 2020].

The electrolytic process with aluminum $(A I)$ electrodes as the anode and cathode thereby, produce controlled quantities of coagulants through the following reactions:

$$
\text { Anode } \quad A l(s) \rightarrow A l^{3+}+3 e^{-}
$$

Cathode $3 \mathrm{H}_{2} \mathrm{O}+3 e^{-} \rightarrow \frac{3}{2} \mathrm{H}_{2}(g)+3 \mathrm{OH}^{-}$

The resulting $\mathrm{Al}^{3+}$ and $\mathrm{OH}^{-}$ions react to form many monomeric species, which eventually form aluminum hydroxide $\left[\mathrm{Al}(\mathrm{OH})_{3}\right]$. [Nawarkar and
Salkar, 2019] in concentrations that are dependent on the current intensity and treatment time.

$$
\mathrm{Al}^{3+}+3 \mathrm{H}_{2} \mathrm{O} \rightarrow \mathrm{Al}(\mathrm{OH})_{3}+3 \mathrm{H}^{+}
$$

The formed $\mathrm{Al}(\mathrm{OH})_{3}$ absorbs and agglomerates the colloidal particles for subsequent flotation and precipitation [Nidheesh, 2020; Mollah et al., 2004]. The retrieved solids contain aluminum originating from the sacrificial electrode, although in lower concentrations, given the control of current and treatment times of the electrocoagulation process.

There have been several reports on utilization of electrocoagulation for the treatment of wastewater with high organic content [Azarian et al., 2018; Mores et al., 2018]; however, this technology has not been tested in sea wastewater such as pump water, which has higher ionic content due to dissolved salts $(3.5 \%)$ and high content of organic matter. Moreover, using chemicals in the treatment of pump water from fishing industries results in negative impact on treatment costs and retrieval of low-quality solids (sludge) with high metal content and low value, which limits its application. In view of these issues, this study aims at assessing the efficiency of electrocoagulation for the removal of TSS from pump water resulting from fish flour industries and optimizing the abovementioned process using Response Surface Methodology (RSM).

\section{MATERIALS AND METHODS}

\section{Pump Water}

Pump water collected from a fishing industry was used to mimic real treatment conditions. In general, most plants use sea water to transport fish.

Table 1. Chemical and biological characteristics of the effluent

\begin{tabular}{|l|c|c|}
\hline \multicolumn{1}{|c|}{ Parameter } & Unit & Value \\
\hline Initial TSS & $\mathrm{mg} / \mathrm{L}$ & 12,360 \\
\hline Oils and fats & $\mathrm{mg} / \mathrm{L}$ & 520 \\
\hline $\mathrm{pH}$ & -- & 6.13 \\
\hline Conductivity & $\mathrm{mS}$ & 40.10 \\
\hline Initial turbidity & $\mathrm{NTU}$ & 9,260 \\
\hline BOD & $\mathrm{mg} / \mathrm{L}$ & 8,290 \\
\hline COD & $\mathrm{mg} / \mathrm{L}$ & 32,971 \\
\hline
\end{tabular}


Sea water has high concentration of salts, which leads to its high conductivity, a parameter directly affecting the electric current. (see Table 1).

\section{Electrocoagulation Reactor}

A transparent acrylic batch reactor with dimensions of $20 \mathrm{~cm} \times 30 \mathrm{~cm} \times 35 \mathrm{~cm}$ (width, length, and height, respectively) was used, with a capacity for treating $10 \mathrm{~L}$ of wastewater. A total of 10 aluminum electrodes were used ( 5 as the anode and 5 as the cathode), whose size was $10 \mathrm{~cm}$ in width and $10 \mathrm{~cm}$ in length, thus covering an area of $100 \mathrm{~cm}^{2}$. A considerable volume was available for sludge collection, given the accumulation of significant amounts of such sludge in the reactor. Figure 1 below illustrates the electrode configuration in the reactor.

\section{Experimental Tests}

Two factors were considered in the experimental pump water tests: current intensity and treatment times. This was done in three stages at current intensities of 7, 10, and $13 \mathrm{~A}$ and the samples were taken at $0,20,30$, and $40 \mathrm{~min}-$ utes. DR1900 Hach portable spectrophotometer was used to measure the TSS concentration. The removal percentage of total suspended solids (TSS) was determined using equation (4), as shown below:

$$
y=\% R=\left(\frac{\left[S S T_{i}\right]-\left[S S T_{f}\right]}{\left[S S T_{i}\right]}\right) \times 100
$$

where: \%R: Removal Percentage of TSS, $\left[S S T_{f}\right]$ : Final concentration of TSS, $\left[S S T_{i}\right]$ : Initial concentration of TSS

\section{Sludge Analysis}

The sludge collected during electrocoagulation had liquid consistency and was centrifuged at $3000 \mathrm{~g}$ for 20 minutes, before disposing the supernatant. The resulting precipitates were dried at $70^{\circ} \mathrm{C}$ for 16 hours in a forced air convection heater and dust ground for analysis. The ash content was determined by following FAO recommendations [Food and Agriculture Organization of the United Nations, 1986], in a muffle furnace at $500{ }^{\circ} \mathrm{C}$ until constant weight; sodium chloride $(\mathrm{NaCl})$ by argentometry using an automatic titrator (Easy Cl Titrator de Mettler Toledo); phosphorous (P) using the 965.17 Association of Official Analytical Chemists (AOAC) photometric technique; potassium (K), iron (Fe), and zinc ( $\mathrm{Zn})$ using Atomic Absorption spectrometry (AA) 975.03 AOAC acetylene air flame; and Al was quantified by AA, as per the instructions of the Perkin Elmer equipment, using a nitrous-acetylene oxide torch on diluted ashes in $1 \mathrm{~N}$ hydrochloric acid $(\mathrm{HCl})$.

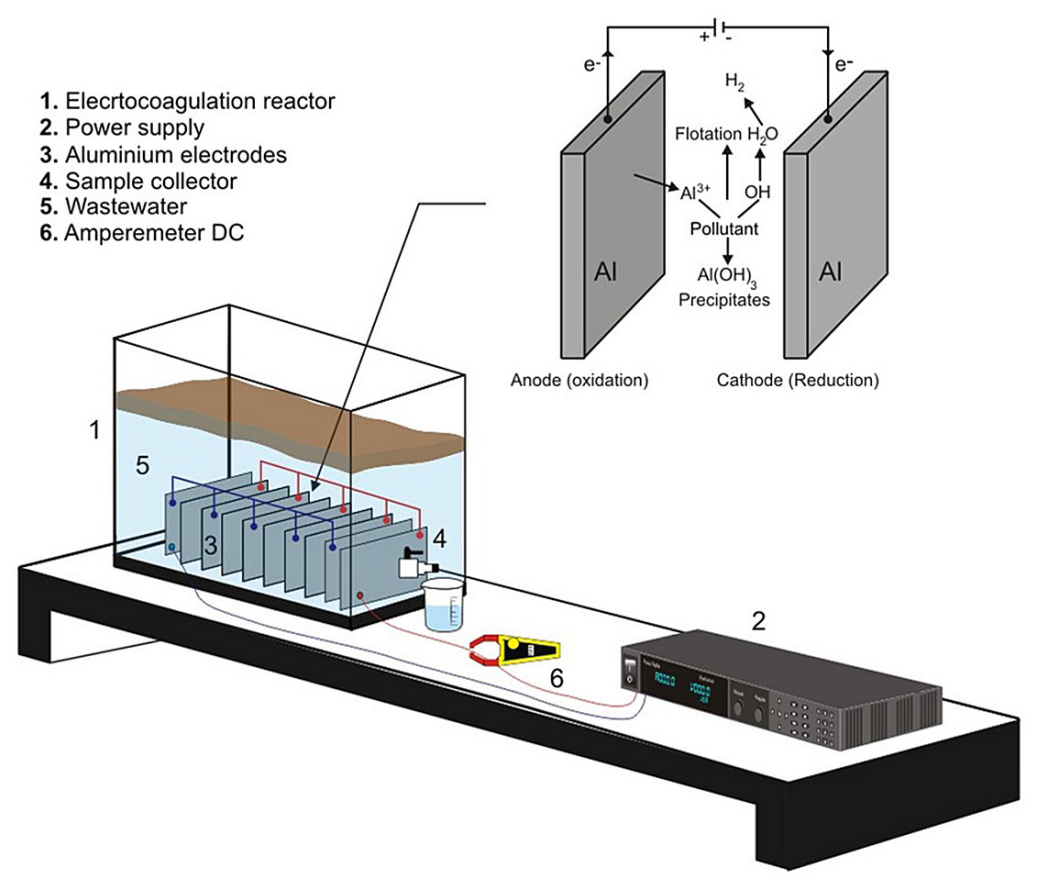

Figure 1. Schematic of the electrocoagulation reactor 


\section{Experimental Design using Response Surface Methodology (RSM)}

RSM was used, based on a full $3^{\mathrm{k}}$ factorial design, with two factors [electrical current intensity $\left(\chi_{1}\right)$ and treatment time $\left.\left(\chi_{2}\right)\right]$ and three levels $(-1,0,+1)$ (see Table 2$)$. Nine experiments were performed with their nine replicates and two core points. RSM is composed of mathematical techniques applied for the improvement and optimization of complex systems [Choi et al., 2020; Basri et al., 2007]. This method is used to assess the effects of different parameters and their interactions in the response of the system. [Choi et al., 2020; Xu et al., 2015].

Equation (5) denotes the second order polynomial equation used in RSM, which evaluates each of the independent variables at its three levels.

$$
\begin{aligned}
y_{i}= & b_{0}+\sum_{i=1}^{n} b_{i} x_{i}+\sum_{i=1}^{n} b_{i i} x_{i}{ }^{2}+ \\
& +\sum_{i=1}^{n-1} \sum_{j=i+1}^{n} b_{i j} x_{i} x_{j}
\end{aligned}
$$

where: $y_{i}$ is the response variable;

$x_{i}$ and $x_{j}$ are the independent variables; and $b_{0}, b_{i}, b_{i i}$ and $b_{i j}$ are the compensation terms, linear coefficients, quadratic coefficients, and interaction coefficients, respectively [Khan et al., 2019]. Design Expert 11.1 software was used to assess the interaction between the factors and the response variable as well as to obtain the analysis of variance (ANOVA) at 95\% confidence level.

\section{RESULTS AND DISCUSSION}

\section{Results from the RSM}

Table 3 contains the $3^{\mathrm{k}}$ factorial response surface design, considering the factors, current

Table 2. Ranges and levels of independent variables

\begin{tabular}{|c|c|c|c|c|}
\hline \multirow{2}{*}{ Factor } & \multirow{2}{*}{ Variables } & \multicolumn{3}{|c|}{ Levels } \\
\cline { 3 - 5 } & & -1 & 0 & +1 \\
\hline$\chi_{1}$ & Intensity (A) & 7 & 10 & 13 \\
\hline$\chi_{2}$ & Time (min) & 20 & 30 & 40 \\
\hline
\end{tabular}

intensity $\left(\chi_{1}\right)$ and treatment time $\left(\chi_{2}\right)$ with the mentioned 3 levels over 20 experiments. Using multiple regression analysis, the response $(y)$ was correlated with the design factors $\left(\chi_{1}, \chi_{2}\right)$ using the second order polynomial [see equation (5)].

To assess the significant variables, the $\mathrm{p}$ and $\mathrm{F}$ values of the response variables, using ANOVA, are shown in Table 4. The results indicated that current intensity $\left(\chi_{1}\right)$ and treatment time $\left(\chi_{2}\right)$ had a significant impact at $95 \%$ confidence level (p $<0.05$ ) on the TSS removal. A model value of $F$ of 32.89 and a probability $>F$ of less than 0.0001 implies that this model is statistically significant. The high values of $\mathrm{R}^{2}$ close to 1 reveal a satisfactory agreement between the results obtained and those predicted [Sefatjoo et al., 2020; Dil et al., 2019]. The quadratic regression model for TSS removal $(y)$, in terms of the coded factors, is shown in Table 5.

Figure 2 indicates the predicted values versus experimental values obtained for TSS removal. The resulting data points were observed to be well distributed near a straight line, thereby indicating a good correlation. Figure 3 depicts the threeand two-dimensional response surface graphs, in terms of two independent factors, which provide a clearer understanding of the primary effects of the interaction. [Dil et al., 2019].

\section{Optimization of Electrocoagulation for TSS removal}

One of the main objectives of this study was to find the optimal parameters for maximization of TSS removal. For this purpose, the variables, current intensity and time, were optimized using RSM to obtain maximum efficiency for TSS removal. The optimal values obtained for the current intensity and time were $13 \mathrm{~A}$ and 30 minutes, respectively, which resulted in a maximum TSS removal of $99.9 \%$. The experimental value of TSS removal using the optimal conditions was $98.36 \%$, which is extremely close to the optimized value and, hence, confirms the importance of the model.

\section{Effect of Current Intensity}

The efficiency of contaminant removal through electrocoagulation is directly proportional to the current intensity, as explained by the Faraday's Law [Azarian et al., 2018; Nariyan et al., 2017]. Generally, on increasing the current intensity, the removal efficiency is also increased. 
Table 3. Experimental design

\begin{tabular}{|c|c|c|c|c|c|c|c|}
\hline & & & & Current intensity (A) & Time (minutes) & \multicolumn{2}{c|}{ TSS removal (\%) } \\
\hline Run & Block & \multicolumn{2}{|c|}{ Levels } & $\chi_{1}$ & $\chi_{2}$ & Experimental & Predicted \\
\hline 1 & 1 & -1 & -1 & 7 & 20 & 61.00 & 65.89 \\
\hline 2 & 1 & 0 & -1 & 10 & 20 & 82.00 & 81.88 \\
\hline 3 & 1 & 1 & -1 & 13 & 20 & 97.00 & 94.73 \\
\hline 4 & 1 & -1 & 0 & 7 & 30 & 97.00 & 90.55 \\
\hline 5 & 1 & 0 & 0 & 10 & 30 & 98.00 & 99.56 \\
\hline 6 & 1 & 1 & 0 & 13 & 30 & 99.00 & 96.39 \\
\hline 7 & 1 & -1 & 1 & 7 & 40 & 98.00 & 98.54 \\
\hline 8 & 1 & 0 & 1 & 10 & 40 & 99.00 & 99.55 \\
\hline 9 & 1 & 1 & 1 & 13 & 40 & 99.00 & 103.38 \\
\hline 10 & 1 & 0 & 0 & 10 & 30 & 99.00 & 98.54 \\
\hline 11 & 2 & -1 & -1 & 7 & 20 & 63.00 & 64.89 \\
\hline 12 & 2 & 0 & -1 & 10 & 20 & 84.00 & 80.88 \\
\hline 13 & 2 & 1 & -1 & 13 & 20 & 95.00 & 93.73 \\
\hline 14 & 2 & -1 & 0 & 7 & 30 & 94.00 & 89.55 \\
\hline 15 & 2 & 0 & 0 & 10 & 30 & 96.00 & 98.56 \\
\hline 16 & 2 & 1 & 0 & 13 & 30 & 97.00 & 98.55 \\
\hline 17 & 2 & -1 & 1 & 7 & 40 & 96.00 & 97.54 \\
\hline 18 & 2 & 0 & 1 & 10 & 40 & 97.00 & 102.38 \\
\hline 19 & 2 & 1 & 1 & 13 & 40 & 99.00 & 95.39 \\
\hline 20 & 2 & 0 & 0 & 10 & 30 & 98.00 & 97.54 \\
\hline
\end{tabular}

Table 4. Statistical analyses of variance using the Response Surface Methodology (RSM) Quadratic Model

\begin{tabular}{|c|c|c|c|c|c|c|c|}
\hline \multicolumn{3}{|c|}{ Source } & Sum of Square & df & Mean Square & $\mathrm{F}$ & $\mathrm{p}$ \\
\hline \multicolumn{3}{|l|}{ Block } & 5.00 & 1 & 5.00 & & \\
\hline \multicolumn{3}{|l|}{ Model } & 2267.57 & 5 & 453.51 & 31.32 & $<0.0001$ \\
\hline \multicolumn{3}{|c|}{$\chi_{1}:$ Current intensity $(\mathrm{A})$} & 494.08 & 1 & 494.08 & 34.12 & $<0.0001$ \\
\hline \multicolumn{3}{|c|}{$\chi_{2}:$ Time (min) } & 936.33 & 1 & 936.33 & 64.67 & $<0.0001$ \\
\hline \multicolumn{3}{|l|}{$\chi_{1} \chi_{2}$} & 512.00 & 1 & 512.00 & 35.36 & $<0.0001$ \\
\hline \multicolumn{3}{|l|}{$x_{1}^{2}$} & 11.52 & 1 & 11.52 & 0.79 & 0.3885 \\
\hline \multicolumn{3}{|l|}{$x_{2}^{2}$} & 285.48 & 1 & 285.48 & 19.72 & 0.0007 \\
\hline \multicolumn{3}{|l|}{ Residual } & 188.23 & 13 & 14.48 & & \\
\hline \multicolumn{3}{|l|}{ Lack of Fit } & 185.73 & 11 & 16.88 & 13.51 & 0.0709 \\
\hline \multicolumn{3}{|l|}{ Pure Error } & 2.50 & 2 & 1.25 & & \\
\hline Cor Total & 2460.80 & 19 & & & & & \\
\hline
\end{tabular}

Current intensities of 7, 10, and 13 A were used over a fixed surface area of $100 \mathrm{~cm}^{2}$ of the aluminum electrodes, connected in parallel. In Figure 3 a) and b) it can be observed that the TSS removal efficiency increases rapidly as the current increases from 7 to $10 \mathrm{~A}$. The corresponding removal percentage increases from $67 \%$ to $88 \%$, respectively. On the contrary, when the current intensity increases from 10 to $13 \mathrm{~A}$, the removal percentage only increases slightly.

Similar results were obtained by [AlJabery et al., 2020] and [Karichappan et al., 2014], indicating a rapid increase in TSS removal as the current increases. This is explained by the increase of the $\mathrm{Al}^{3+}$ cations and the consequent $\mathrm{Al}(\mathrm{OH})_{3}$ particles released by the anode when the current density increases [Deveci et al., 2019; Deghles and Kurt, 2016]. However, the application of a high current intensity can cause a decrease in the removal efficiency [Holt et al., 2002]. This may be attributed to the observation that the rate of hydrogen gas released from the cathode increases despite the increase in the amount of $\mathrm{Al}$ delivered to the medium. As the amount 


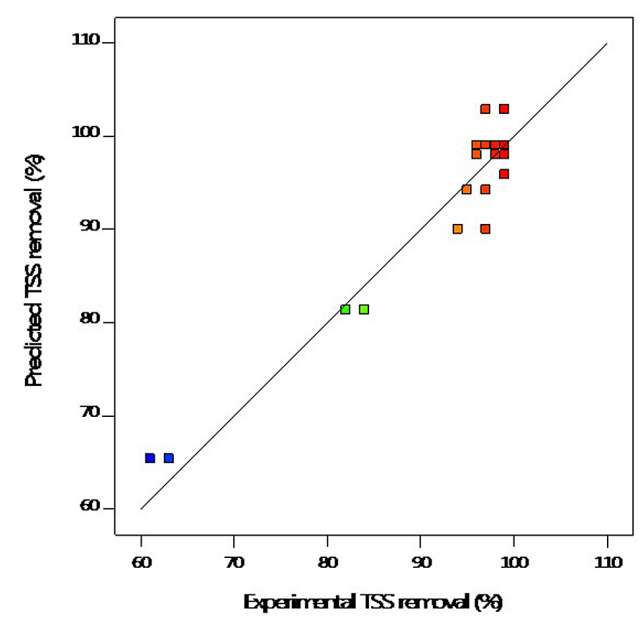

Figure 2. Regression plot illustrating the correlation between experimental data and predicted values obtained using the Response Surface Methodology, describing percentage removal of total suspended solids (TSS)

of hydrogen bubbles increases, they stick more readily to the crystals of the coagulant and are rapidly deposited on the reactor surface by flotation [Bayar et al., 2011]. This causes flocculation and does not allow the coagulant to be mixed with the contaminants for removal. Furthermore, the efficiency of the current intensity is directly related to the $\mathrm{pH}$. At low $\mathrm{pH}$ values, an increase in current intensity causes efficiency to decrease [Deveci, 2019; Phalakornkule et al., 2010]. Hence, electrocoagulation using aluminum electrodes should be operated under neutral or higher conditions to obtain optimal results [Deveci et al., 2019; Adhoum et al., 2004].

\section{Effect of Treatment Time}

The increase in the reaction time is directly proportional to the removal of the contaminant. As it may be observed in Figure 3, TSS removal efficiency increases as the treatment time increases to 30 minutes. Thereafter, removal efficiency tends to be constant. This is consistent with the findings of [Saad, 2019] and [Al-Qodah,2018], who asserted that removal tends to be constant after 28 minutes, because the rate of generation of cationic metal ions increases with increasing reaction time, which implies an improvement in the efficiency of removal of the contaminant [Priya and Jeyanthi, 2019; Nawarkar and Salkar, 2019]. However, long reaction time accelerates the reaction and destabilizes the colloids that eventually reduce the zeta potential of the particles. This zeta potential should be close to zero to achieve maximum efficiency for the removal of the contaminants [Priya and Jeyanthi, 2019]. At the same time, $\mathrm{OH}^{-}$ions are produced at the cathode, which increases with increase in reaction time, resulting in the formation of aluminum-hydro complexes and flocs [Montero et al., 2007]. A prolonged reaction time influences the loss of mass of the electrode and the cost of the process; hence, there is a need to determine the optimal time for the treatment.

\section{Effect on the Sludge Obtained}

The ash content in the sludge is around $20 \%$, and a third of it comprises salt from the seawater used for pumping and is directly related to the amount of salt water that was not removed during centrifugation and is trapped in the precipitate. The higher current intensity associated with the longer treatment time could carry over some metal compounds into the already formed sludge. The contents of $\mathrm{Fe}, \mathrm{K}, \mathrm{Zn}$, and $\mathrm{P}$ in the sludge were not significantly different among the several treatment processes, although it is noteworthy that lower currents coincided with lower concentrations of the metals (see Table 6). On the other hand, the concentration of $\mathrm{Al}$ in the sludge clearly increased due to the formation of salts from the sacrificial electrode, and this concentration had a direct relationship with both the current intensity and time for electrocoagulation. The concentration of $\mathrm{Al}$ in the sludge must be taken into account

Table 5. Statistical parameters obtained using RSM for total suspended solids (TSS) removal (\%)

\begin{tabular}{|c|c|c|c|c|}
\hline \multirow{2}{*}{ Response } & $R^{2}$ & $A d j-R^{2}$ & $p$ & \multirow{2}{*}{ Quadratic model for response based on least squares } \\
\hline & $(\%)$ & $(\%)$ & & \\
\hline TSS removal (\%) & 92.34 & 89.39 & 0.0000 & $\begin{array}{c}y=-115.73+13.3929 x_{1}+8.17857 x_{2}- \\
-0.266667 x_{1} x_{2}-0.162698 x_{1}^{2}-0.0771429 x_{2}^{2}\end{array}$ \\
\hline
\end{tabular}



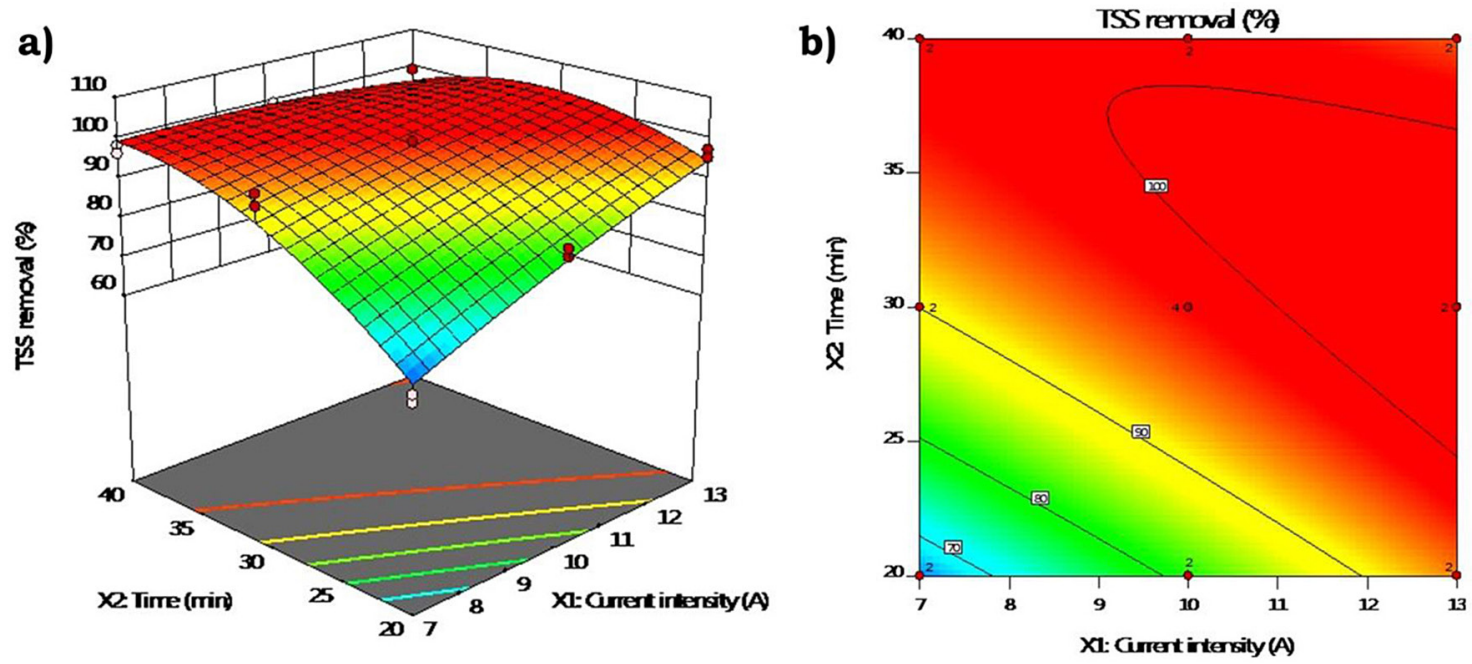

Figure 3. Effect of the current intensity $\left(\chi_{1}\right)$ and time $\left(\chi_{2}\right)$ on TSS removal percentage $(y)$ as indicated by a) response surface graph and b) two-dimensional outline graph

Table 6. Dry content of ash, salts, and metals in sludge from electrocoagulation of pump water

\begin{tabular}{|c|c|c|c|c|c|c|c|c|c|c|}
\hline Run & Block & $\begin{array}{c}\text { Current } \\
\text { intensity (A) }\end{array}$ & $\begin{array}{c}\text { Time } \\
\text { (min) }\end{array}$ & $\begin{array}{c}\text { Ashes\% } \\
\text { (dry content) }\end{array}$ & $\begin{array}{c}\text { NaCl\% } \\
\text { (dry content) }\end{array}$ & $\begin{array}{c}\text { Al\% } \\
\text { (dry content) }\end{array}$ & $\begin{array}{c}\mathrm{Fe} \% \\
\text { (dry content) }\end{array}$ & $\begin{array}{c}\mathrm{K} \% \\
\text { (dry content) }\end{array}$ & $\begin{array}{c}\text { Zn ppm } \\
\text { (dry content) }\end{array}$ & $\begin{array}{c}\text { P\% } \\
\text { (dry content) }\end{array}$ \\
\hline 1 & 1 & 7 & 20 & 19.00 & 6.55 & 1.88 & 0.34 & 0.41 & 240 & 2.56 \\
\hline 2 & 1 & 10 & 20 & 29.67 & 6.55 & 1.95 & 0.33 & 0.42 & 261 & 2.37 \\
\hline 3 & 1 & 13 & 20 & 19.03 & 6.11 & 1.77 & 0.31 & 0.40 & 259 & 2.27 \\
\hline 4 & 1 & 7 & 30 & 19.37 & 6.33 & 1.92 & 0.33 & 0.41 & 264 & 2.65 \\
\hline 5 & 1 & 10 & 30 & 20.05 & 6.99 & 1.78 & 0.30 & 0.42 & 269 & 2.65 \\
\hline 6 & 1 & 13 & 30 & 19.27 & 6.21 & 1.67 & 0.31 & 0.38 & 256 & 2.12 \\
\hline 7 & 1 & 7 & 40 & 20.09 & 6.13 & 2.01 & 0.31 & 0.40 & 260 & 2.65 \\
\hline 8 & 1 & 10 & 40 & 20.04 & 6.26 & 2.03 & 0.30 & 0.40 & 267 & 2.37 \\
\hline 9 & 1 & 13 & 40 & 20.12 & 6.24 & 2.01 & 0.30 & 0.41 & 250 & 2.37 \\
\hline 10 & 1 & 10 & 30 & 21.00 & 6.05 & 2.14 & 0.29 & 0.40 & 247 & 2.46 \\
\hline 11 & 2 & 7 & 20 & 19.29 & 6.92 & 1.53 & 0.31 & 0.40 & 224 & 2.06 \\
\hline 12 & 2 & 10 & 20 & 11.97 & 7.00 & 1.86 & 0.34 & 0.45 & 255 & 2.44 \\
\hline 13 & 2 & 13 & 20 & 17.30 & 6.01 & 1.55 & 0.36 & 0.36 & 278 & 2.05 \\
\hline 14 & 2 & 7 & 30 & 21.38 & 6.66 & 1.84 & 0.25 & 0.44 & 256 & 2.53 \\
\hline 15 & 2 & 10 & 30 & 22.79 & 7.48 & 1.56 & 0.22 & 0.42 & 309 & 2.30 \\
\hline 16 & 2 & 13 & 30 & 18.72 & 6.14 & 1.35 & 0.28 & 0.35 & 212 & 1.90 \\
\hline 17 & 2 & 7 & 40 & 20.71 & 5.74 & 2.00 & 0.28 & 0.39 & 263 & 2.39 \\
\hline 18 & 2 & 10 & 40 & 20.30 & 5.42 & 2.28 & 0.37 & 0.41 & 207 & 2.58 \\
\hline 19 & 2 & 13 & 40 & 20.55 & 7.02 & 2.02 & 0.24 & 0.41 & 250 & 2.19 \\
\hline 20 & 2 & 10 & 30 & 23.00 & 5.92 & 2.59 & 0.30 & 0.42 & 243 & 2.58 \\
\hline
\end{tabular}

when considering a possible use of the sludge as feed or fertilizer, because of the toxicity associated with the innate metal [Vitorello et al., 2005].

\section{CONCLUSIONS}

This study proved that electrocoagulation using $\mathrm{Al}$ electrodes is effective in removing TSS from pump wastewater generated in the processing of fishmeal. Analysis of the experimental design indicated that the current intensity and treatment time influenced the removal of TSS. The value of $\mathrm{R}^{2}$ obtained for TSS was $92.32 \%$, which indicates good conformance with the second order regression model. The optimal operating conditions for TSS removal were $\mathrm{I}=13 \mathrm{~A}$ and $\mathrm{t}=30$ minutes. Using these conditions, $99.9 \%$ removal efficiency for TSS was obtained. However, it should also be noted that the $\mathrm{Al}$ content in the sludge increased in treatment processes at higher current intensities over longer time. 


\section{Acknowledgement}

To the Instituto de Investigación Científica (IDIC) of the Universidad de Lima, Pesquera Diamante S. A., Instituto Tecnológico de la Producción (ITP) and the Programa Nacional de Innovación en Pesca y Acuicultura (PNIPA)-PESSIA-PP-000001, Contract: No. 141-2018, for fully supporting the development of this study.

\section{REFERENCES}

1. Adhoum N., Monser L., Bellakhal N., Belgaied J.E. 2004. Treatment of electroplating wastewater containing $\mathrm{Cu} 2+, \mathrm{Zn} 2+$ and $\mathrm{Cr}(\mathrm{VI})$ by electrocoagulation. Journal of Hazardous Materials, 112(3), 207-213. https://doi.org/10.1016/j. jhazmat.2004.04.018

2. Akansha J., Nidheesh P.V., Gopinath A., Anupama K.V., Suresh Kumar M. 2020. Treatment of dairy industry wastewater by combined aerated electrocoagulation and phytoremediation process. Chemosphere, 253, 126652

3. AlJaberi F.Y. 2019. Operating cost analysis of a concentric aluminum tubes electrodes electrocoagulation reactor, Heliyon, 5(8), e02307, https:// doi.org/10.1016/j.heliyon.2019.e02307

4. AlJabery F.Y., Ahmed S.A., Makki H.F. 2020. Electrocoagulation treatment of high saline oily wastewater: evaluation and optimization. Heliyon, 6(6), e03988. https://doi.org/10.1016/j.heliyon.2020. e03988

5. Al-Qodah, Z.; Al-Shannag, M. 2018. On the Performance of Free Radicals Combined Electrocoagulation Treatment Processes. Separation Science and Technology, 48(2), 1-16. https://doi.org/10.1080/0 1496395.2017.1373677

6. Azarian G., Rahmani A.R., Atashzaban Z., Nematollahi D. 2018. New batch electro-coagulation process for treatment and recovery of high organic load and low volume egg processing industry wastewater. Process Safety and Environmental Protection, 119, 96-103. https://doi.org/10.1016/j.psep.2018.07.025

7. Basri M., Rahman R.N.Z.R.A., Ebrahimpour A., Salleh A.B., Gunawan E.R., Rahman M.B.A. 2007. Comparison of estimation capabilities of Response Surface Methodology (RSM) with artificial neural network (ANN) in lipase-catalyzed synthesis of palm-based wax ester. BMC Biotechnology, 7, 53. https://doi.org/10.1186/1472-6750-7-53

8. Bayar S., Yıldız Y.Ş., Yılmaz A.E., İrdemez Ş. 2011. The effect of stirring speed and current density on removal efficiency of poultry slaughterhouse wastewater by electrocoagulation method. Desalination, 280(1-3), 103-107.
9. Castañeda L.F., Coreño O., Nava José L., Carreño G. 2020. Removal of fluoride and hydrated silica from underground water by electrocoagulation in a flow channel reactor. Chemosphere, 244, 125417. https:// doi.org/10.1016/j.chemosphere.2019.125417

10. Ching Y.C., Redzwan G. 2017. Biological treatment of fish processing saline wastewater for reuse as liquid fertilizer. Sustainability, 9(7), 1062. https:// doi.org/10.3390/su9071062

11. Choi A.E.S., Futalan C.C.M., Yee J.J. 2020. Fuzzy optimization for the removal of uranium from mine 1 water using batch electrocoagulation: A case study. Nuclear Energy and Technology, 52(7), 1471-1480. https://doi.org/10.1016/j.net.2019.12.016

12. Cristóvão R.O., Botelho C.M., Martins R.J., Loureiro J.M., Boaventura R.A.R. 2014. Primary treatment optimization of a fish canning wastewater from a Portuguese plant. Water Resources and Industry, 6, 51-63

13. Deghles A., Kurt U. 2016. Treatment of tannery wastewater by a hybrid electrocoagulation/electrodialysis process. Chemical Engineering and Processing: Process Intensification, 104, 43-50. https:// doi.org/10.1016/j.cep.2016.02.009

14. Deveci E.Ü., Akarsu C., Gönen Ç., Özay Y. 2019. Enhancing treatability of tannery wastewater by integrated process of electrocoagulation and fungal via using RSM in an economic perspective. Process. Biochemistry, 84, 124-133. https://doi. org/10.1016/j.procbio.2019.06.016

15. Dil E.A., Ghaedi M., Asfaram A., Mehrabi F., Sadeghfar F. 2019. Efficient adsorption of Azure B onto CNTs/Zn:ZnO@Ni2P-NCs from aqueous solution in the presence of ultrasound wave based on multivariate optimization. Journal of Industrial and Engineering Chemistry, 74, 55-62. https://doi. org/10.1016/j.jiec.2018.12.050

16. Elkacmi R., Boudouch O., Hasib A., Bouzaid M., Bennajah M. 2020. Photovoltaic electrocoagulation treatment of olive mill wastewater using an external-loop airlift reactor Sustainable Chemistry and Pharmacy 17, 100274. https://doi.org/10.1016/j. scp. 2020.100274

17. Espinoza Villegas M.I. 2016. Proposal for the addition of sludge recovered from pump water to improve fishmeal productivity at a Fishing Company. Universidad Nacional de Trujillo. http://dspace.unitru. edu.pe/bitstream/handle/UNITRU/7853/Tesis\%20 Maestr\%c3\%adaX\%20-\%20Manuel\%20I.\%20Espinoza $\% 20$ Villegas.pdf? sequence $=1 \&$ is Allowed $=\mathrm{y}$

18. Food and Agriculture Organization of the United Nations. 1986. Manuals of food quality control 8: Food analysis, quality, adulteration, and tests of identity. http://www.fao.org/3/W6530E/W6530E.pdf

19. Holt P.K., Barton G.W., Wark M., Mitchell C.A. 2002. A quantitative comparison between chemical 
dosing and electrocoagulation. Colloids and Surfaces A: Physicochemical and Engineering Aspects, 211(2-3), 233-248. https://doi.org/10.1016/ S0927-7757(02)00285-6

20. Karichappan T., Venkatachalam S., Jeganathan P. M. 2014. Optimization of electrocoagulation process to treat grey wastewater in batch mode using Response Surface Methodology. Journal of Environmental Health Science and Engineering, 12(1), 29. https://doi.org/10.1186/2052-336X-12-29

21. Khan S.U., Islam D.T., Farooqi I.H., Ayub S., Basheer F. 2019. Hexavalent chromium removal in an electrocoagulation column reactor: Process optimization using $\mathrm{CCD}$, adsorption kinetics and $\mathrm{pH}$ modulated sludge formation. Process Safety and Environmental Protection, 122, 118-130. https:// doi.org/10.1016/j.psep.2018.11.024

22. Loza Pacheco R.B. 2014. Determination of the optimal dosage of coagulants and flocculants applied to a continuous system through flotation in the treatment of fishing effluents. Universidad $\mathrm{Na}$ cional de San Agustín. http://repositorio.unsa.edu. pe/bitstream/handle/UNSA/3989/IQloparb063. pdf? sequence $=1 \&$ isAllowed $=y$

23. Ministry of Environment. 2018. Executive Order No. 010-2018-MINAM. Perú. https://sinia.minam. gob.pe/normas/aprueban-limites-maximos-permisibles-efluentes-establecimientos.

24. Mollah M., Morkovsky P., Gomes J., Kesmez M., Parga J. \& Cocke D. 2004. Fundamentals, present and future perspectives of electrocoagulation. Journal of Hazardous Materials, 114, 199-210.https:// doi.org/10.1016/j.jhazmat.2004.08.009

25. Montero C., Maldonado A., Solorza-Feria O. 2007. Arsenic Removal from Underground Water by Electrocoagulation with Zinc, Brass, and Iron. ECS Transactions, 2(13), 71-85. https://doi. org/10.1149/1.2424301.

26. Mores R., Mello P.D.A., Zakrzevski C.A., Treichel H., Kunz A., Steffens J., Dallago R.M. 2018. Reduction of soluble organic carbon and removal of total phosphorus and metals from swine wastewater by electrocoagulation. Brazilian Journal of Chemical Engineering, 35(4), 1231-1240. https://doi.org/10 .1590/0104-6632.20180354s20170300

27. Nariyan E., Sillanpää M., Wolkersdorfer C. 2017. Electrocoagulation treatment of mine water from the deepest working European metal mine - Performance, isotherm and kinetic studies. Separation and Purification Technology, 177, 363-373.

28. Nawarkar C.J., Salkar V.D. 2019. Solar powered electrocoagulation system for municipal wastewater treatment. Fuel, 237, 222-226. https:// doi.org/10.1016/j.fuel.2018.09.140

29. Nidheesh P.V., Kumar A., Syam Babu D., Scaria J., Suresh Kumar M. 2020. Treatment of mixed industrial wastewater by electrocoagulation and indirect electrochemical oxidation. Chemosphere, 251, 126437.

30. Omil F., Méndez R., Lema J.M. 1996. Anaerobic treatment of seafood processing waste water in an industrial anaerobic pilot plant. Water S. Part A, 22, 173-181.

31. Phalakornkule C., Mangmeemak J., Intrachod K., Nuntakumjorn B. 2010. Pretreatment of palm oil mill effluent by electrocoagulation and coagulation. ScienceAsia, 36(2), 142-149

32. Priya M., Jeyanthi J. 2019. Removal of COD, oil and grease from automobile washwater effluent using electrocoagulation technique. Microchemical Journal, 150, 104070. https://doi.org/10.1016/j. microc.2019.104070

33. Putra A.A., Watari T., Maki S., Hatamoto M., Yamaguchi T. 2020. Anaerobic baffled reactor to treat fishmeal wastewater with high organic content. Environmental Technology and Innovation 17, 100586. http://dx.doi.org/10.1016/j.eti.2019.100586

34. Rodríguez C.T.C., Amaya-Chavez A., Roa-Morales G., Barrera-Díaz C.E., Ureña-Núñez F. 2010. An integrated electrocoagulation phytoremediation process for the treatment of mixed industrial wastewater. International Journal of Phytoremediation 12(8), 772-784.

35. Saad H., Ammar Natheer N., Ismail Ali D., Ali Wisam M., Abbas. 2019. Electrocoagulation technique for refinery wastewater treatment in an internal loop split-plate airlift reactor. Journal of Environmental Chemical Engineering, 7(6), 103489. https://doi.org/10.1016/j.jece.103489

36. Sefatjoo P., Alavi Moghaddam M.R.A., Mehrabadi A.R. 2020. Evaluating electrocoagulation pretreatment prior to reverse osmosis system for simultaneous scaling and colloidal fouling mitigation: Application of RSM in performance and cost optimization. Journal of Water Process Engineering, 35, 101201. https://doi.org/10.1016/j.jwpe.2020.101201

37. Vitorello V.A., Capaldi F.R., Stefanuto V.A. 2005. Recent advances in aluminum toxicity and resistance in higher plants. Brazilian Journal of Plant Physiology, 17(1), 129-143.

38. Xu C., Wang J., Yang T., Chen X., Liu X., Ding X. 2015. Adsorption of uranium by amidoximated chitosan-grafted polyacrylonitrile, using Response Surface Methodology. Carbohydrate Polymers, 121, 79-85. https://doi.org/10.1016/j. carbpol.2014.12.024 